\title{
ANALISIS TERHADAP SERING RUSAKNYA LOUDSPEAKER DI MASJID LUQMANUL HAKIM POLBAN
}

\author{
Tata Supriyadi ${ }^{1}$, Ashari ${ }^{1}$, Ridwan Solihin ${ }^{1}$, Ferry Satria ${ }^{1}$, Slameta ${ }^{1}$, Budi Setiadi ${ }^{1}$ \\ ${ }^{1}$ Jurusan Teknik Elektro Politeknik Negeri Bandung \\ Email: tata.supriyadi@polban.ac.id
}

\begin{abstract}
Abstrak
Masjid merupakan salah satu tempat untuk menyampaian pesan moral dari para penceramah, khotib, ustad, guru ngaji kepada para jamaahnya. Kualitas audio yang baik dan jelas dalam masid menjadi suatu keharusan. Ketika sistem tata suara di mesjid terganggu seperti suara tidak jelas, muncul feedback bahkan hal terburuk sampai speakernya mengalami kerusakan akan menjadi masalah bagi para jamaah untuk menerima informasi dari para penceramah. Hal ini terjadi di Masjid Luqmanul Hakim POLBAN. Delapan buah speaker dinding $60 \mathrm{~W} 8 \Omega$ yang terpasang sering sekali mengalami kerusakan. Speaker tersebut dicatu oleh 2 buah Amplifier Stereo dengan total daya keluaran 480W tiap kanal. Tidak dipasang alat Sound Compressor atau limiter mengakibatkan speaker menjadi rentan terhadap kerusakan ketika ada kenaikan daya akibat feecback atau setting volume terlalu besar. Metode yang dilakukan untuk mengatasi masalah tersebut yaitu melakukan observasi dan analisis spesifikasi dan istalasi pada peralatan sound system yang sudah terpasang. Ada dua opsi untuk mengatasi masalah salah instalasi sound system tersebut. Pertama speaker dipertahankan maka Amplifier diganti dengan yang memiliki daya keluaran per kanal maksimum $120 \mathrm{~W}$ di impedansi $8 \Omega$. Atau diganti speaker dengan yang memiliki daya total per kanal 480W. Dari ujicoba lapangan dipilih opsi 2 oleh pengelola masjid dan hanya satu Amplifier saja yang digunakan. Hasil setelah tiap kanal dipasang masing-masing 2 buah speaker $240 \mathrm{~W} / 8 \Omega$ secara paralel diperoleh suara yang cukup jelas tanpa distorsi dengan besar SPL rata-rata 72,9dB dan setelah dilakukan ujicoba selama 3 bulan tidak ada masalah.
\end{abstract}

Kata kunci: Analisis kerusakan, sound system, speaker, amplifier.

\section{PENDAHULUAN}

Masjid merupakan tempat ibadah umat Islam. Selain kegiatan ibadah rutin shalat lima waktu dan salat jumat, banyak pula kegiatan positif lainnya yang dilakukan di masjid seperti ceramah, men- toring, merayakan hari besar keagamaan, kegiatan akad nikah dan sebagainya. Untuk mendukung kegiatan di lingkungan masjid perlu didukung oleh sarana dan prasarana ibadah yang memadai. Salah satunya adalah sistem tata suara yang baik. Sistem tata suara yang 
DIFUSI

Volume 3, No.2 Juli 2020

baik tentunya memenuhi syarat dari sisi tingkat kekerasan suara yang cukup merata di setiap bagian ruangan, kejelasan suara pembicara supaya mudah dipahami apa yang disampaikan, memenuhi standar akustik dan estetika yang baik dari sisi penempatan speaker.

Selain peralatan yang tata suara yang memadai dalam pengoperasian seharihari perlu pengelolaan peralatan sound system dengan baik. Penanganan peralatan oleh tenaga operator yang tidak terampil bisa mengakibatkan buruknya suara yang dihasilkan seperti suara distorsi atau clipping, sering timbul feedback saat digunakan. Hal yang lebih buruk lagi adalah sering rusaknya peralatan sound system seperti loudspeaker ataupun amplifier. Rusaknya peralatan tersebut bisa disebabkan oleh tidak tepatnya setting peralatan oleh operator atau bisa juga karena salah dalam disain awal instalasi peralatan tata suaranya.

Beberapa tulisan yang telah dipublikasi banyak yang membahas masalah sistem tata suara, baik itu sistem tata suara di masjid, gereja, bandara dan sebagainya. Mariani dan N. Raul, telah memaparkan kondisi objektif akustik sebuah ruang Masjid di kota Makasar. Kondisi awal akustik ruang masjid yang diamati secara subjektif adalah distribusi suara yang tidak merata di dalam ruang serta bunyi dengung dan gema yang menimbulkan ketidaknyamanan audien saat mendengarkan suara penceramah. Untuk memperbaikinya dilakukan setting dan pengukuran ulang sisi akustiknya [1].

Riyanto dan Munaji [2] melalui kegiatan Pengabdian Iptek bagi Masyarakat telah melakukan penataan ulang sistem tata suara di Masjid Darusalam Janti Slahung. Pada kegiatan ini telah berhasil menata ulang dengan cara mengganti instalasi dan peralatan lama dengan yang baru.

Sagala [3] sudah melakukan analisis pengaruh kebisingan terhadap performansi Public Address System Terminal 1 di Bandara Soekarno Hatta. Tingkat kebisingan di Bandara fungsi dari banyaknya orang waktu keberangkatan dan kedatangan pesawat. Dalam studinya telah dilakukan untuk mengatasi tingkat kebisingan yang berbeda setiap saat dengan memasang Automatic Volume Control. Volume suara akan meningkat Sound Pressure Level (SPL) nya ketika bising dan menurun lagi ketika mulai sunyi.

Dari beberapa tulisan belum ada yang membahas analisis atau studi tentang bagaimana cara mengatasi sering rusaknya perangkat speaker atau amplifier di tata suara masjid. Hal ini kadang menjadi fenomena yang sering terjadi dan perlu diberikan pengetahuan bagi operator atau pengelola masjid untuk mengantisipasinya. Pada penelitian kali ini akan dilakukan sebuah studi analisis terhadap sering rusaknya loudspeaker yang ada di Masjid Luqmanul Hakim Politeknik Negeri Bandung.

\section{METODE}

Penelitian dilakukan dalam beberapa tahapan yang disesuaikan dengan kondisi lapangan di lingkungan Masjid Luqmanul Hakim. Adapun langkahlangkahnya adalah: 
DIFUSI

Volume 3, No.2 Juli 2020

\section{Identifikasi Masalah Yang Diha- dapi Mitra}

Identifikasi masalah yang dihadapi mitra dengan cara melakukan wawancara dengan para pengurus masjid, pihak Yayasan LH dan Operator Sound System masjid LH. Kegiatan identifikasi ini untuk mengetahui seberapa sering terjadi kerusakan dan dalam kondisi pengoperasian seperti apa.

\section{Analisis Permasalahan}

Analisis masalah adalah peninjauan langsung sistem instalasi dan peralatan sound sistem yang terpasang. Lebih detailnya yaitu mencatat semua spesifikasi peralatan yang terpasang untuk data masukan saat menganalisa sistem.

\section{Penyelesaian Permasalahan yang Dihadapi Mitra}

Setelah diketahui permasalahannya selanjutnya diusulkan langkah perbaikan sistem yang tepat sesuai dengan masalah yang ada sehingga masalah tersebut tidak muncul lagi.

\section{Ujicoba Sistem Setelah Perbaikan}

Uji coba merupakan langkah teknis yang harus dilakukan untuk pengujian fungsionalitas, kekuatan suara atau Sound Pressure Level (SPL), ketahanan daya speaker, kejelasan suara, masalah gema dan masalah feedback dengan cara mengatur ulang peralatan sound system dengan perangkat yang baru.
Langkah terakhir adalah evaluasi dari pengguna. Di evaluasi ini diminta pendapat audien yang sering menggunakan masjid untuk kegiatan salat lima waktu, salat jumat, saat khutbah, dan acara lain-lainnya. Dari hasil wawancara ini bisa diperoleh hasil evaluasinya dan diambil kesimpulan dari kegiatan penelitian ini.

\section{HASIL DAN PEMBAHASAN}

\section{Hasil Identifikasi dan Analisis}

Setelah dilakukan proses observasi, identifikasi dan analisis masalah terhadap sering rusaknya loudspeaker yang ada di lantai utama dan lantai 2 Masjid Luqmanul Hakim POLBAN, maka tampak permasalahannya adalah tidak adanya kesesuaian sistem Amplifier yang digunakan dengan spesifikasi loudspeaker yang terpasang termasuk masalah instalasinya.

Gambar 1 memperlihatkan kondisi eksisting pada saat dilakukan observasi jaringan instalasi tata suara di Masjid Luqmanul Hakim POLBAN. Masingmasing lantai utama dan lantai 2 terpasang 4 buah loudspeaker. Tiap 2 loudspeaker diparalel dan dihubungkan masing-masing dengan salahsatu output amplifier. Spesifikasi Loudspeaker berdaya $60 \mathrm{~W}$ dengan impedansi $16 \Omega$, sedangkan Amplifiernya mempunyai spesifikasi daya output $480 \mathrm{~W}$ di Impedansi $8 \Omega$.

\section{Evaluasi}




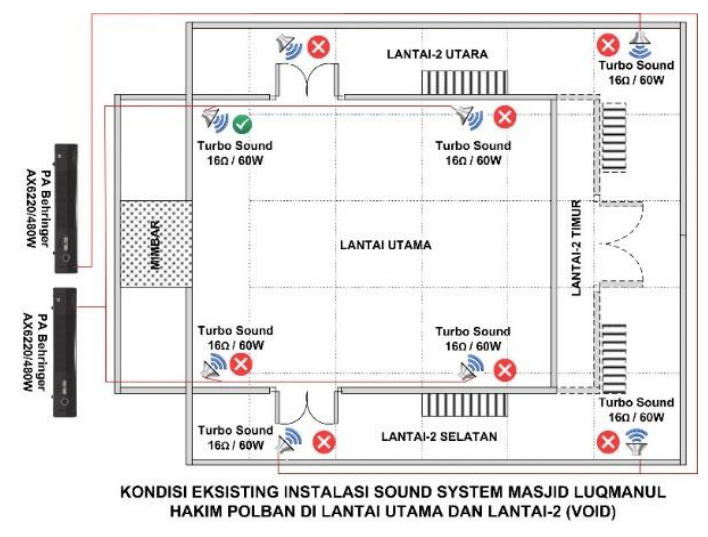

Gambar 1. Kondisi Eksisting Instalasi Sound System di Lantai Utama dan Lantai 2 Masjid

Permasalahan sering rusaknya speaker di lantai utama dan lantai dua Masjid dikarenakan daya speaker merk Turbo Sound tipe IMPACT TCI52-T seperti yang ditunjukan pada Gambar 2 mempunyai daya kontinyu $60 \mathrm{~W}$ dan Daya Puncak 240W dengan impedansi $16 \Omega$, masih belum sesuai dengan pasangan Power Amplifier merk Behringer tipe AX6220 dengan total daya outputnya 480W seperti ditunjukan pada Gambar 4 , dengan Impedansi $8 \Omega$ meskipun sudah dipasang paralel untuk tiap kanalnya [4-5]. Sering rusaknya speaker karena daya puncak speaker nilainya masih dibawah daya maksimum amplifiernya, sehingga ketika setting volume terlalu besar dan muncul feedback mengakibatkan speaker jadi overload.

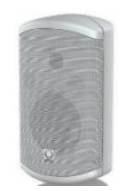

Gambar 2. Speaker Turbo Sound TCI52-T, 60W kontinyu, 240W Puncak, impedansi $16 \Omega$, 6 inch

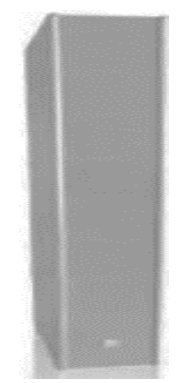

Gambar 3 Speaker TOA ZS-S240CW, 240W kontinyu, 480W Puncak, impedansi $16 \Omega, 6$ inch

\section{Technical Specifications \\ Power Output L0-Z AX6220 \\ Peak, $1 \%$ THD, $1 \mathrm{kHz}$ sine wave \\ Stereo (both channels driven) \\ - $8 \Omega$ per channel $\quad 480 \mathrm{~W}$ \\ - $4 \Omega$ per channel $\quad 900 \mathrm{~W}$

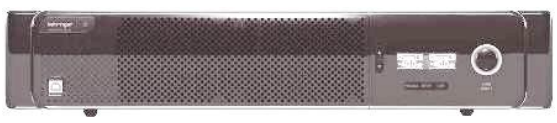 \\ Gambar 4. Spesifikasi Power Amplifier Behringer tipe AX6220}

\section{Penyelesaian Masalah}

Ada 2 opsi perbaikan yaitu Speaker tetap dipertahankan, amplifier diganti atau opsi kedua Amplifier tetap, speaker yang diganti. Bila opsi satu diambil berarti diperlukan daya amplifier total sebesar $8 \times 60 \mathrm{~W}=480 \mathrm{~W}$. Bila instalasi yang ada dipertahankan tiap saluran 2 buah speaker diparalel, maka diperlukah amplifier low impedance $8 \Omega$ dengan daya per kanal $120 \mathrm{~W}$. Bisa menggunakan 2 buah Amplifier stereo. Bila ingin kemudahan dalam mengistalasi bisa menggunakan 2 buah Amplifier High Impedance $240 \mathrm{~W} / 100 \mathrm{~V}$. Pemasangannya cukup diparalel per 4 buah speaker dengan catatan speaker Turbo Soundnya disetting di High Impedance bukan di $16 \Omega$. Dengan cara ini speaker akan lebih awet karena dibantu matching im- 
DIFUSI

Volume 3, No.2 Juli 2020

pedance transformator yang membatasi dayanya tidak melebihi $60 \mathrm{~W}$.

Opsi kedua yaitu mempertahankan Amplifier dan mengganti speaker. Karena daya Amplifier sebesar $480 \mathrm{~W} 8 \Omega$ per kanalnya, maka perlu dipasang speaker yang mampu menyerap daya dari Amplifier tanpa terjadi Clipping atau Overload. Bila daya speaker diperbesar maka jumlahnya tidak perlu sampai 8 buah karena ukuran ruangan tetap. Cukup dipasang 2 buah speaker tiap lantai. Berarti bila satu kanal amplifier $480 \mathrm{~W}$ cukup dipasang per kanal 2 buah speaker 240 W. Jadi untuk kedua lantai hanya perlu sebuah Amplifier.

Dari opsi yang ditawarkan pihak mitra atau Pengurus Yayasan Luqmanul Hakim memilih opsi kedua dengan alasan Amplifier mempunyai daya yang besar dan harganyapun relatif mahal. Karena Amplifier yang dipertahankan, maka kami memilihkan loudspeaker yang mampu menerima kekuatan daya dari amplifiernya. Pilihannya ada pada speaker low impedance merk TOA Tipe Slim Array ZS-S240CW-AS yang mempunyai daya $240 \mathrm{~W}$ kontinyu, $480 \mathrm{~W}$ peak seperti ditunjukan pada Gambar 3 [5]. Untuk lebih jelasnya perubahan instalasi sebelum dan sesudah penataan ulang ditunjukan pada Gambar 5.

\section{Hasil Pengujian Sound Pressure Level}

Setelah pemasangan instalasi speaker yang baru tahapan berikutnya adalah pengujian fungsional dan pengukuran tingkat kekerasan suara atau Sound Pressure Level (SPL) dalam batas yang wajar dan jelas untuk enak didengar.
Posisi speaker terletak di ketinggian 4 meter dari lantai dan sudut kemiringannya diarahkan supaya area tembaknya ke ruang tengah pada tiap lantainya. Gambar 6 menunjukan titik-titik lokasi pengambilan atau pengukuran SPL. Lokasi pengukuran di Lantai Utama diambil 9 titik yaitu berdasarkan 3 shaf depan, tengah, belakang dan 3 posisi utara, sejajar mimbar dan selatan. Sedangkan di Lantai 2 hanya diambil 5 titik saja karena lantainya berbentuk void. Hasil pengukuran SPL di tiap titik ditampilkan pada Tabel 1 .
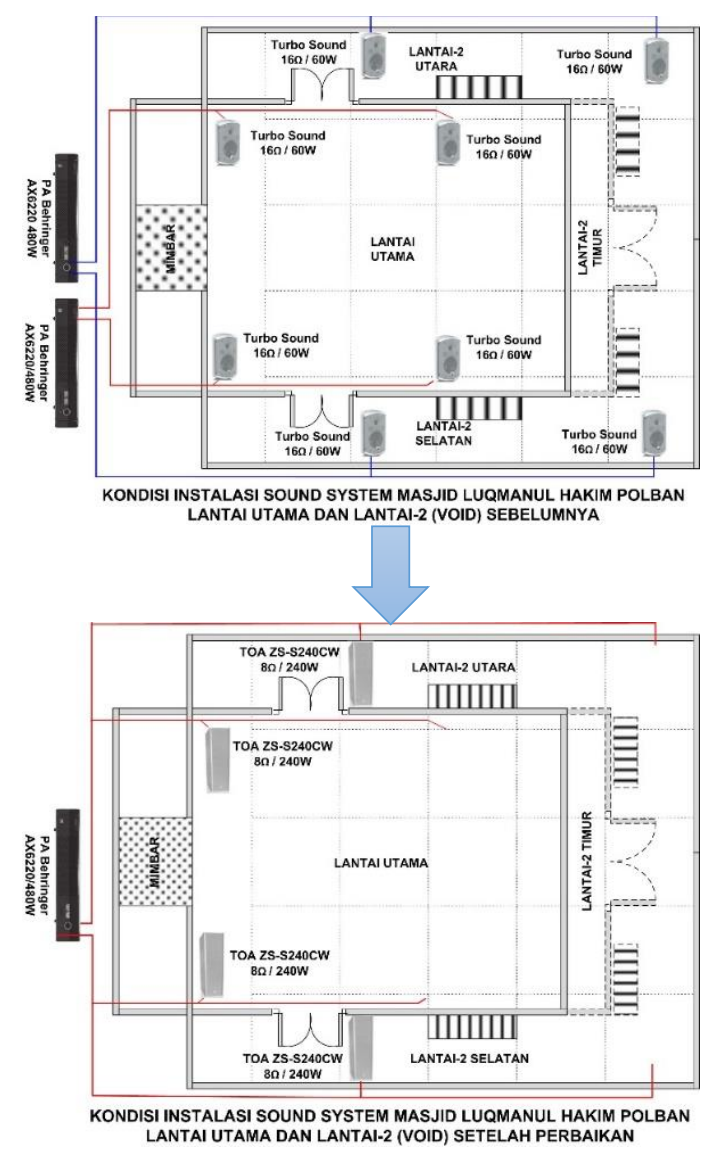

Gambar 5. Kondisi Sebelum dan Sesudah Penataan Ulang di Lantai Utama dan Lantai 2 


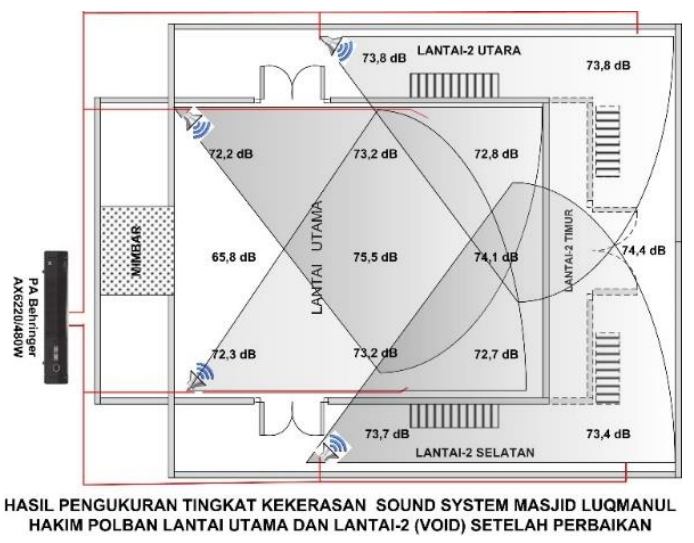

Gambar 6. Hasil Pengukuran SPL di Lantai Utama dan Lantai 2

Dari hasil pengujian SPL diperoleh hasil dengan nilai terkecil 65,8 dB ada di area shaf depan sejajar mimbar, sedangkan nilai terbesar ada di tengah sejajar mimbar. Sehubungan dengan menggunakan jenis speaker TOA Tipe Array mengakibatkan sudut daerah jangkauan sempit tidak terlalu lebar. Posisi speaker di sudut mengakibatkan area depan mimbar jadi daerah di luar jangkauan tembak speaker. Seharusnya speaker agak digeser posisinya ke tengah. Namun karena alasan estetika maka posisinya tetap dipertahankan di sudut. Hasil SPL terbesar ada di daerah tengah atau sejajar dengan mimbar. Hal ini terjadi karean area tengah ini merupakan irisan dari jangkauan tembak dari 2 buah speaker. Tetapi secara keseluruhan diperoleh ratarata SPL di besaran 72,9 dB. Sebuah nilai yang cukup untuk tingkat kekerasan yang dibutuhkan oleh sebuah ruangan Masjid yang tingkat kebisingan sekitarnya tidak terlalu tinggi.

Durasi pengujian operasional saat kegiatan penelitian ini berlangsung selama kurun 3 bulan setelah perbaikan instalasi. Berdasarkan hasil pengamatan di lapangan selama itu tidak ada keluhan lagi speaker yang rusak atau kurang jelas suaranya.

Tabel 1. Hasil Pengujian SPL di Lantai Utama dan Lantai 2 Masjid Luqmanul Hakim

\begin{tabular}{|c|c|c|c|c|}
\hline No & Posisi di Lantai 1 & $\begin{array}{l}\text { SPL } \\
\text { (dB) }\end{array}$ & Posisi di Lantai 2 & $\begin{array}{l}\text { SPL } \\
(d B)\end{array}$ \\
\hline 1 & Shaf Depan Utara & 72,2 & & \\
\hline 2 & Shaf Depan sejajar Mimbar & 65,8 & & \\
\hline 3 & Shaf Depan Selatan & 72,1 & & \\
\hline 4 & Shaf Tengah Utara & 73,2 & & \\
\hline 5 & Shaf Tengah sejajar Mimbar & 75,5 & Shaf Tengah Utara & 73,8 \\
\hline 6 & Shaf Tengah Selatan & 73,2 & Shaf Tengah Selatan & 73,7 \\
\hline 7 & Shaf Belakang Utara & 72,8 & Shaf Belakang Utara & 73,8 \\
\hline 8 & Shaf Belakang sejajar Mimbar & 74,1 & $\begin{array}{l}\text { Shaf Belakang sejajar } \\
\text { Mimbar }\end{array}$ & 74,4 \\
\hline 9 & Shaf Belakang Selatan & 72,7 & Shaf Belakang Selatan & 73,4 \\
\hline \multicolumn{4}{|c|}{ Rata-rata } & 72,9 \\
\hline
\end{tabular}


DIFUSI

Volume 3, No.2 Juli 2020

\section{KESIMPULAN}

Berdasarkan hasil observasi, analisis dan solusi yang diberikan dapat diambil kesimpulan bahwa sebelumnya telah terjadi salah perancangan sound sistem di Masjid Luqmanul Hakim POLBAN dengan tidak sesuainya pemilihan spesifikasi daya antara speaker dan amplifiernya. Setelah perancangan ulang dilakukan dengan memilih daya amplifier dan speaker yang sesuai, tidak ada lagi keluhan sering rusaknya speaker di Masjid Luqmanul Hakim.

Saran untuk pihak Yayasan Masjid Luqmanul POLBAN setelah dilakukannya pembenahan supaya bisa menjaga kondisi keberlangsungan sistem tata suaranya dengan menunjuk operator yang paham dalam megoperasikan peralatan sound system tersebut.

\section{UCAPAN TERIMAKASIH}

Penulis mengucapkan banyak terima kasih kepada pihak UPPM POLBAN yang telah memfasilitasi dan membiayai kegiatan penelitian ini melalui skema Program Kemitraan Pengabdian Pada
Masyarakat dari dana PNBP POLBAN tahun 2019. Ucapan terima kasih juga kepada pihak Yayasan Luqmanul Hakim yang telah membantu dalam pelaksanaan di lapangan.

\section{REFERENSI}

[1] Mariani, "Deskripsi Kondisi Akustik Ruang Masjid Al Markaz Al Islami Makasar," Jurnal SMARTek, Vol. 6, no. 4, Nopember, 2008.

[2] D. Riyanto, "IbM Pegeras Suara Masjid Darusalam Janti Slantung," Jurnal Dedikasi Masyarakat, Vol. 2 No. 1, Oktober, 2018.

[3] M. Y. Sagala, "Analisa Pengaruh Kebisingan terhadap Performansi Public Adres System Terminal 1 Bandara Soekarno-Hatta," Jurnal Ilmiah Teknik Elektro, Fak. Teknik, Universitas Mercu Buana, Jakarta, Vol.1, 2015.

[4] Manual Users Speaker Turbo Sound TCI52-T

[5] Manual Users Power Amplifier Behringer tipe AX6220

[6] Manual Users Speaker TOA ZSS240CW. 